\title{
Factors Associated with the Emotional Intelligence among Youth University Students
}

\author{
Ibtissam Sabbah, Hala Sabbah, Rania Khamis, Reve Berbari, Sanaa Sabbah, Sally Badran, and Nabil \\ Droubi
}

\section{ABSTRACT}

Nowadays, emotional intelligence (EI) is an emerging topic for psychological, educational, and management researchers and consultants. EI is the ability to manage emotions and interact effectively with others. The purpose of our study is to assess the level of EI of young university students and its associated factors; and to develop a valid and reliable instrument of EI in Lebanon. During 2018, a cross-sectional study, which enrolled 705 university students chosen randomly in seven faculties was conducted. The survey included questions on socio-demographic characteristics, health behaviors, Wong and Law Emotional Intelligence Scale (WLEIS). The attitudes related to media and technology usage assessed by using the last four sub-factors of the Media and Technology Usage and Attitudes Scale. The translation and cultural adaptation of the WLEIS followed a standardized protocol. After that, the psychometric properties of the scale (i.e., feasibility, reliability, and validity) were evaluated. A total of 705 undergraduates filled out the questionnaire, of whom $74 \%$ were females, aged from 17 to 35 (mean $=20.42 \pm 2.41)$ years. The rotated principal axis factor analysis produced four-factors, explaining $64.60 \%$ of the variance, corresponding to the hypothesized Self-Emotions Appraisal (SEA), OthersEmotions Appraisal (OEA), Use of Emotion (UOE), and Regulation of Emotion (ROE) scales of WLEIS. The internal consistency of the WLEIS scale was high for all subscales (Cronbach's alpha $>0.70$ ). The mean OEA score was significantly higher in females as compared to males $(p=0.03)$. The students who study in public university and have physical activities had higher scores of the ROE ( $p<0.001)$; whereas the drinkers of alcohol $(p=0.04)$ and smokers had lower scores $(p=0.001)$. The relationship between SEA, OEA, UOE scores and academic performance was significant $(p<0.001)$. The UOE and ROE were negatively and significantly correlated with the Dependence on Technology $(r=-0.15 ; p<0.001)$. This study supports the feasibility, reliability, and validity of the WLEIS Arabic version as a screening tool of EI among young university students. The individuals working with students in the context of improving academic skills may want to routinely assess EI of their students in order to improve education, student development, personal well-being, and mental ability.

Keywords: Academic achievement, Ability Emotional Intelligence, Wong and Law Emotional Intelligence Scale (WLEIS), Media and Technology Usage and Attitudes Scale (MUTAS), Young University Students.

\section{INTRODUCTION}

Nowadays, emotional intelligence (EI) is an emerging topic for psychological, educational, and management researchers and consultants [1]. EI is the ability to manage emotions and interact effectively with others [2]. EI is the capability to have a precise insight of appraising, to articulate one's own, and others' emotions and to retrieve and create feelings as soon as they facilitate thinking [3], [4]. People with high EIs are sensitive to the moods and temperaments of others, display empathy, appreciate multiple perspectives
Published Online: December 27, 2020

ISSN: $2736-5476$

DOI: :10.24018/clinicmed.2020.1.1.3

Ibtissam Sabbah*

Faculty of Public Health, Lebanese University, Saida, Lebanon.

(e-mail: ibtissam.sabbah@ul.edu.lb)

Hala Sabbah

Faculty of Economic Sciences and Business Administration, Lebanese University, Nabatieh, Lebanon.

(e-mail: hsabbah@ul.edu.lb)

Rania Khamis

Institute of Social Science, Lebanese University, Saida, Lebanon.

(e-mail: Rania.khamis@ul.edu.lb)

Reve Berbari

Faculty of Public Health, Lebanese University, Saida, Lebanon.

(e-mail: rricha@ndu.edu.lb)

Sanaa Sabbah

Institute of Social Science, Lebanese University, Saida, Lebanon.

Doctoral School of Literature, Humanities \& Social Sciences, Lebanese University, Beirut, Lebanon. (e-mail: Sanaa.Sabbah_@ul.edu.lb) Sally Badran

Maroun Semaan Faculty of engineering and architecture, American University of Beirut, Beirut, Lebanon.

(e-mail: smb45@mail.aub.edu)

Nabil Droubi

MD, Saida, Lebanon.

(e-mail: nsdroubi_@inco.com.lb)

*Corresponding Author when approaching situations [2], and employ emotions in problem resolution [4]. EI has its roots in the concept of "social intelligence" that was first identified by Thorndike in 1920 who defined social intelligence as "the ability to understand and manage men and women, boys and girls - to act wisely in human relations" [5]. Reuven Bar-On also investigated and defined EI from a competency model perspective [6]. Salovey and Mayer were among the earliest to propose the EI concept to refer to the ability of a person to deal with his or her emotions [7], [8]. EI consists of three broad and interrelated abilities: (1) the appraisal and 
expression of emotion, (2) the regulation of emotion, and (3) the utilization of emotion to motivate and plan [9].

Theoretical paradigms subdivide EI into three levels: knowledge, ability, and trait. The knowledge level refers to knowing EI-related techniques that help keep focus on the task and regulate one's own emotions but does not necessarily mean that one is able to put this knowledge into practice. The ability level refers to being able to perform a certain emotion regulation strategy when one is explicitly prompted to do so; however it does not necessarily mean that one will do so frequently nor in every situation. Finally, the trait level refers to habitual dispositions - what people usually do when dealing with emotional situations [9]. The Trait model envisages EI as " $a$ constellation of emotional selfperceptions located at the lower levels of personality" [10]; it refers to an individual's self-perceptions of their emotional abilities.

Research has shown that EI is expected to be linked to a range of theoretically interesting outcomes. Proponents of the EI concept argue that emotional intelligence affects people's physical health [1], mental health [1], psychological wellbeing [7], and academic achievement [11], [12]. In addition, it is positively related to the job satisfaction [5], job performance [1], [7], [12], performance of leaders [5], and occupational stress [7]. Many studies show that an individual's success is related to elements of EI such as high motivation, high self-confidence, and teamwork [13]. The emotions play an important role in a profession that requires not only technical expertise but also psychologically oriented care, knowledge about the self and emotions [8]. In nursing, EI would be crucial to further development and growth of the profession concept [8]. In medicine, an indirect negative correlation was established between a physician's level of EI and his or her medico legal risk (risk of litigation) [14].

The majority of students entering university are aged between 18 and 21, a transition age to adulthood characterized by dramatic changes in life [15]. Young age is a time of growth, during which students move to an environment that expects more autonomy and has a firmer academic focus with less individualized emotional support [9]. The youth are particularly vulnerable in the face of today's rapidly changing labor markets, decent work deficits, difficult job transitions, and increasing demands for twentyfirst-century skills, leading to career indecision and delays in joining the labor force [16]. In addition to that, technology has become a big problem university students who use it, and it has a direct impact on their life [17] as it has become an option for learning [18]. Social media has provided a platform in which students are under a lot of pressure to live up to the expectations of the social media images. It shapes their interests, their body images perception, their lifestyles [17], their mental health, and their emotional intelligence [19], [20]. Therefore, understanding and investing in factors that promote the youth's career readiness and twenty-first-century skills have been timelier and more important internationally [16].

The emotion is an essential element of one's personality and quality of life. So, the EI has emerged as an important construct in research on positive youth development which is linked to successful adaptation, social integration, and wellbeing [21]. Students better develop their emotional intelligence during their education before beginning work [22]. It is essential to master the emotions present in the learning process, understood as a continuum in the internalization of teaching based on a social process of enrichment, communication, and collaboration marked by orientation toward quality and continuous improvement in the acquisition of knowledge [18]. In this way, it is important to say that the acquisition of knowledge is mediated by emotions. If a positive climate is offered in the university environment for the mastery of optimized emotional management, the experiences of multiple teachings are strengthened and reach completeness in their internalization and implementation by individuals [18]. For inculcating such attributes in the youth, emotional intelligence coupled with an enriched personality mark as core competencies for the advisors and counselors for providing effective counseling services [4]. Training programs are required to support their development at universities where human relations are extremely important [22]. Certain medical schools assess the smartest students according to the highest grade point averages and the Medical College Admission Test (MCAT) scores. However, the medical profession must start recognizing the importance of EI in the assessment if they hope to identify and train a phenomenal next generation of caring, effective physicians who can lead multidisciplinary teams, and induce patient behavior change [2].

Several studies assessed the EI in Arabic Countries into both perspectives: the trait and or ability [3], [10], [13], [23] - [27]. In Lebanon, the role of emotions in the formation of young students has been scarcely studied. The available information of mental health and Role-Emotional of this age group remain limited to studies of health related quality of life [28]. Sanchez-Ruiz et al [29] studied psychosocial (i.e., personality dimensions, trait EI, and media pressure) and weight-related variables as predictors of eating disorders (ED) in Lebanese university students [29]. Obeid et al. [30] assessed risk factors associated with alexithymia in a sample of the Lebanese population. El Hassan \& El Sader [31] adapted and validated the BarOn Emotional Quotient Inventory: Youth Version (BarOn EQ-i:YV) as a measure of emotional intelligence of a sample of 433 students in the 10to 18-year-old age group [31]:

Under the ability model, one of the main self-report instruments is the Wong and Law Emotional Intelligence Scale (WLEIS). It was developed in Hong Kong (Asia), its original language is English [1]. Since the emergence of the WLEIS, there has been great interest in using this instrument in different countries. The WLEIS has been supported in China [32], Far Eastern country (Singapore) and a Western European country (Belgium) [33], Spain [34]. It was culturally adapted in Arabic in Morocco [3], and in Malaysia [13]. When an instrument such as the WLEIS is used in an international context, it is imperative to establish that the measurement structure underlying the scores is equivalent cross-culturally. Research questions for the study are as follows: (1) what is the level of emotional intelligence among the respondents? (2) What is the relationship between the respondents' emotional intelligence and their socio demographic characteristics, their academic performance, and their attitude toward technology using a valid and reliable instrument of EI in Lebanon? 
Consequently, our aim was to assess the level of EI of young university students and its associated factors especially the academic performance and attitudes toward technology; and to develop a valid and reliable instrument of EI in Lebanon.

Our hypotheses were the following: there will no significant difference in EI among students on the basis of gender, socio economic characteristics, lifestyle, academic performance, and attitude toward technology.

\section{MATERIALS AND MethodS}

\section{A. Study Design}

From April to September 2018, a cross-sectional survey was conducted among a population of young university students in the areas of Nabatieh, South, and Mount Lebanon. The faculties that consented to participate were enrolled in our study. After obtaining approval from the Directors of the faculties, data was collected using self-administered questionnaires. The classes were chosen randomly in the faculties whose administrators consented to participate. The students were approached after class and asked to participate in the study. They were informed that the survey was voluntary and confidential. The consent form was presented at the beginning of the questionnaire. A completed questionnaire was presented as evidence of the consent to the study. The investigators, in number of four, were present during several times of the day to ensure the filling out of the questionnaires by the students. The questionnaire took 10 15 minutes to be completed. The target population in the faculties during the academic year 2017-2018 was about 2000. Seven faculties participated in our study, including two in Mount Lebanon, one private and one public, and five in southern Lebanon, three of which were public and two private (the public university is the largest university in Lebanon).

The sample size was determined by adopting the following statistical formula for minimum sample size calculation. According to a population size of 2000 students, a margin of error is $3.64 \%$, a $95 \%$ confidence level, and the response distribution is $50 \%$ (in the absence of similar local studies), the minimal sample size needed was 700 students distributed to all the faculties concerned (http://www.raosoft.com/samplesize.html). So the sample was between 100 and 150 students for each faculty.

\section{B. Questionnaire}

The study questionnaire included four sections. The first section developed by the authors of this study contained questions on demographic characteristics of the study participants. The respondents were asked to fill in several questions on their demographic profile (gender, age, residency area, living with parents (yes/no), specialization, and current occupation. Health behaviors (smoking, alcohol consumption, and physical activities) were also self-reported by the students.

In the second section of the questionnaire, the academic performance was collected: data was obtained about the Cumulative Grade Point Average (CGPA) of the students for fall 2017-2018.
The attitudes related to media and technology usage were assessed using the last four sub-factors of the Media and Technology Usage and Attitudes Scale (MTUAS). The MUTAS has acceptable validity and reliability in Lebanon [17]. The attitudes related to media and technology usage subscales include 16 items, which comprise four domains: positive attitudes toward technology (six items), anxiety of being without technology/technology dependency (three items), negative attitudes towards technology (three items), and multitasking preferences (four items, one reverse scored). Each question on the test has a point scoring system beside it, using a 5-point Likert structure (strongly agree, agree, neither agree nor disagree, disagree, strongly disagree).

The English and Chinese versions of the Wong and Law Emotional Intelligence Scale (WLEIS) were prepared by Wong and Law. The authors initially proposed this instrument for the study of EI in the workplace. However, its use has spread to other contexts [3], [7], [13]. The WLEIS is considered a short instrument, comprising 16 items that are scored on a seven-point Likert scale (1_totally disagree to 7 _ totally agree) [7]. The WLEIS has high reliability and validity. The Cronbach alpha for all dimensions was between 0.83 and 0.90 . The 16 items in WLEIS consist of four dimensions namely, Self-Emotions Appraisal (SEA), OthersEmotions Appraisal (OEA), Use of Emotion (UOE) and Regulation of Emotion (ROE) [35]. Scales were translated from English to Arabic through an initial translation and a back translation process. Finally, a pretest was conducted. The WLEIS Arabic version was then administered to a representative sample of 20 subjects of lay native Arabic speakers. The group was asked to explain what each item means. Globally, the adaptation did not cause any particular problems.

\section{Statistical analysis}

Statistical analyses were conducted using frequencies, means, and standard deviations (SDs) to describe the characteristics of the participants and the attitudes related to media and technology usage scales scores.

Individual WLEIS items were recoded, summed and transformed, with missing values imputed as recommended. Mean and standard deviations were calculated for the WLEIS since the data was normally distributed. The percentage of people with scores at the ceiling (percentage of subjects with a score of 7) and floor (lowest level=1) were calculated for each scale. On the scale level, ceiling and floor effects should be less than $20 \%$ in order to assume that the scale is capturing the full range of potential responses in the population [36].

The feasibility of the WLEIS was assessed by determining the proportion of missing values per item.

Exploratory factor analysis (EFA) was used for the validity of the structure. Items factor analyses were performed using WLEIS' 16 items. Principal component analysis with and orthogonal varimax rotation was carried out among items to compare the factorial structure of data with that obtained from the original instrument [35]. The validity would be supported if the hypothesized four domains of EI underlying the WLEIS were identified on factor analysis. The average score from a scale is substantially correlated if factor loading is greater than 0.7 , moderately correlated if factor loading is between 0.3 and 0.7 , and slightly correlated if factor loading is less 
than 0.3 [36] - [38]. The reliability of the subscales was measured using Cronbach's alpha coefficients, whereas an alpha above 0.70 was acceptable for group comparisons. The construct validity of the WLEIS was also assessed in terms of known-groups validity and convergent and discriminant validity. The construct validity of the WLEIS would be supported if groups differing in factors known to affect EI had WLEIS scores that varied according to a priori hypotheses. For known-groups validity, we hypothesized that the WLEIS scales scores differ among young students' subgroups i.e. gender, academic performance, and their attitude toward technology. This validity of known groups makes it possible to evaluate at the same time the EI among young students' subgroups.

To assess the construct validity of the WLEIS, we also calculated Spearman's rank correlation coefficient between the WLEIS subscales scores and concepts that measure similar concepts (convergent validity) and concepts that measure different concepts (discriminant validity). Therefore, we assumed positive correlations between the WLEIS and similar constructs (Positive Attitudes to Technology) and negative correlations with WLEIS scale scores versus different constructs, such as Dependence on Technology and Negative Attitudes to Technology.

All statistical analyses were performed by using SPSS version 22.0 (SPSS, Chicago, IL). All tests of significance were two-tailed. P-value $\leq 0.05$ considered to be the critical level of significance.

\section{RESULTS}

A summary of the characteristics of the respondents stratified by gender is presented in Table 1 . The faculties that participated in the study were seven in the three areas: Saida, Nabatieh, and Mount Lebanon. The sample consisted of 705 undergraduates (of which $74 \%$ were females) aged from 17 to 35 (mean $=20.42$; median $=20$ years; $\mathrm{SD}=2.41$ ). $34.5 \%$ live in urban areas. $61.8 \%$ of participants belong to the age range of 20 to 29 years. More than half of respondents live in rural areas $(65.5 \%)$. Nearly one third $(31.3 \%)$ of students were first year students, 39\% second year students, $24.8 \%$ third year students, $4 \%$ fourth year and $0.9 \%$ fifth year students.

Participants were enrolled in various specialties. The majority lived with their parents $(90.8 \%) .27 \%$ of the students indicated that they were employed to help their parents finance their studies. Alcohol consumption was declared by $14 \%$ of respondents, $20.1 \%$ used tobacco, and $62.1 \%$ were physically active. The mean of the Cumulative Grade Point Average (CGPA) was 69.75 (SD=13.01). Half of students had a CGPA between 70 and $100(50 \%)$ (Table 1).

When subjected to a principal axis factor analysis, the rotated solution of the 16 items revealed a four factors solution that accounted for $64.60 \%$ of the variance, corresponding to the hypothesized SEA, OEA, UOE and ROE subscales of WLEIS. The Factors loadings ranged from 0.55 to 0.80 (Table 2). The results of the Kaiser-MeyerOlkin (KMO) index (0.91) ensured the adequacy of the sample.
TABLE 1: CHARACTERISTICS OF THE RESPONDENTS

\begin{tabular}{ll}
\hline \hline Variables & Frequency $(\%)$ \\
\hline University & $205(29.1)$ \\
Private & $500(70.9)$ \\
Public & $275(36.5)$ \\
\hline Age & $436(61.8)$ \\
$17-19$ & $12(1.7)$ \\
$20-29$ & \\
30 and higher & $7(1.0 \%)$ \\
\hline Specialties & $42(6.0 \%)$ \\
Humanities and Education & $76(10.8 \%)$ \\
Engineering & $139(19.7 \%)$ \\
Sciences & $114(16.2 \%)$ \\
Health sciences, & $133(18.9 \%)$ \\
Business Administration and computer sciences & $153(21.7 \%)$, \\
Architecture & $41(5.8 \%)$. \\
Social science & \\
Information sciences & $632(89.6)$ \\
\hline Living with parents & $73(10.4)$ \\
yes & $192(27.2)$ \\
No & $513(72.8)$ \\
\hline Working & \\
Yes & $21(3.3)$ \\
No & $300(46.7)$ \\
\hline Cumulative Grade Point Average (CGPA) & $(\mathrm{n}=642)$ \\
$0-49$ & $321(50)$ \\
$50-69$ & \\
$70-100$ & $99(14)$ \\
\hline Alcohol & $606(86)$ \\
Yes & $142(20.1)$ \\
No & $563(79.9)$ \\
\hline Smoking & $438(62.1)$ \\
Yes & $267(37.9)$ \\
\hline No & \\
Yes & \\
No & \\
\hline Total & \\
\hline
\end{tabular}

Table 3 presents the mean scores (SDs), and skewness, kurtosis of the four domains of WLEIS among the respondents investigated in this study. The Mean WLEIS subscales score in Lebanese youth students was higher as compared to undergraduate students in Hong Kong [7]. The kurtosis and skewness of all scores ranged from -1 to 1 , thus indicating the normality of the data [39] except the skewness and kurtosis of the Use of Emotion (UOE) scale scores that were respectively (-1.26) and 1.68.

The Cronbach alpha coefficients ranged from 0.77 to 0.82 . According to the original version of the WLEIS the internal consistency of the Arabic version of WLEIS subscales was generally good (Table 3).

The mean OEA score was higher in females as compared to males $(p=0.03)$. The students who study in public university and have physical activities had higher scores of the ROE $(\mathrm{p}<0.001)$, whereas the drinkers of alcohol $(\mathrm{p}=0.04)$ and smokers had lower scores $(\mathrm{p}=0.001)$. The relationship between SEA, OEA, UOE scores and academic performance was significant $(p<0.001)$ (Table 4). The UOE and ROE were negatively and significantly correlated with Dependence on Technology and they were only weakly associated $(r=-0.15$; $\mathrm{p}<0.001)$. 
TABLE 2: DESCRIPTION OF ITEMS, FACTOR LOADINGS FROM EXPLORATORY FACTOR ANALYSIS OF THE WLEIS (N =705)

\begin{tabular}{|c|c|c|c|c|c|c|c|}
\hline \multirow[t]{2}{*}{ Items } & \multicolumn{7}{|c|}{ Rotated Principal Components } \\
\hline & Mean & SD & $\begin{array}{l}\text { Factor } 1 \\
\text { ROE }\end{array}$ & $\begin{array}{l}\text { Factor } 2 \\
\text { UOE }\end{array}$ & $\begin{array}{l}\text { Factor } 3 \\
\text { SEA }\end{array}$ & $\begin{array}{l}\text { Factor } 4 \\
\text { OEA }\end{array}$ & Communalities \\
\hline I have a good sense of why I have certain feelings most of the time & 5.11 & 1.64 & .41 & .08 & .66 & .25 & .67 \\
\hline I have a good understanding of my own emotions & 5.36 & 1.60 & .41 & .24 & .70 & .13 & .73 \\
\hline I really understand what I feel & 5.31 & 1.59 & .35 & .25 & .67 & .14 & .65 \\
\hline I always know whether I am happy or not & 5.13 & 1.73 & -.02 & .26 & .76 & .15 & .67 \\
\hline I always know my friends' emotions from their behaviors & 5.63 & 1.36 & .17 & .10 & .10 & .80 & .69 \\
\hline I am a good observer of others' emotions & 5.47 & 1.37 & .30 & .20 & .18 & .72 & .69 \\
\hline I am sensitive to the feelings and emotions of others & 5.65 & 1.43 & .10 & .34 & .02 & .55 & .42 \\
\hline I have a good understanding of the emotions of people around me & 5.55 & 1.42 & .03 & .26 & .32 & .72 & .69 \\
\hline I always set goals for myself and then try my best to achieve them & 5.76 & 1.47 & .23 & .67 & .20 & .31 & .63 \\
\hline I always tell myself I am competent & 5.30 & 1.49 & .24 & .69 & .16 & .16 & .58 \\
\hline I am a self-motivated person & 5.67 & 1.42 & .34 & .71 & .26 & .16 & .71 \\
\hline I always encourage myself to try my best & 6.02 & 1.36 & .01 & .70 & .25 & .35 & .67 \\
\hline I am able to control my temper and handle difficulties rationally & 5.04 & 1.67 & .76 & .25 & .13 & .13 & .68 \\
\hline I am quite capable of controlling my own emotions & 5.18 & 1.70 & 68 & .28 & .33 & .12 & .66 \\
\hline I can always calm down quickly when I am very angry & 4.80 & 1.83 & .74 & .13 & .08 & .14 & .58 \\
\hline I have good control of my own emotions & 5.15 & 1.79 & .71 & .08 & .24 & .15 & .59 \\
\hline
\end{tabular}

Notes: SD= standard deviation; ROE = Regulation of emotion; UOE = Use of emotion; SEA = Self-emotion appraisal; OEA = Other's emotion appraisal; the percentage of measured variance explained by these four factors is $64.49 \%: 42.45 \%$ for the first, $9.70 \%$ of the second, $6.63 \%$ for the third, and $5.71 \%$ for the fourth factor.

TABLE 3: DESCRIPTION AND INTERNAL CONSISTENCY OF THE WLEIS IN COMARISON WITH THE ORIGINAL VERSION [7]

\begin{tabular}{|c|c|c|c|c|}
\hline $\mathrm{N}=705$ & SEA & OEA & UOE & ROE \\
\hline Mean (SD) & $5.23(1.33)$ & $5.75(1.08)$ & $5.68(1.15)$ & $5.05(1.39)$ \\
\hline Skewness & -0.75 & -0.98 & -1.26 & -0.63 \\
\hline Kurtosis & -.02 & 1.09 & 1.68 & -.13 \\
\hline \multicolumn{5}{|l|}{ Quartiles } \\
\hline $25^{\text {th }}$ & 4.50 & 5.00 & 5.0 & 4.0 \\
\hline $50^{\text {th }}($ median $)$ & 5.50 & 5.25 & 6.0 & 5.25 \\
\hline $75^{\text {th }}$ & 6.25 & 6.25 & 6.5 & 6.0 \\
\hline Floor \% & .3 & .1 & .4 & 1.0 \\
\hline Ceiling \% & 8.9 & 10.2 & 13.0 & 8.4 \\
\hline Cronbach Alpha & 0.82 & 0.77 & 0.81 & 0.81 \\
\hline Number of items & 4 & 4 & 4 & 4 \\
\hline $\begin{array}{l}\text { Mean (SD) of the WLEIS } \\
\text { original version }\end{array}$ & $4.01(1.05)$ & $4.15(0.96)$ & $4.09(0.92)$ & $3.78(1.12)$ \\
\hline $\begin{array}{l}\text { Cronbach Alpha of the WLEIS } \\
\text { original version }\end{array}$ & .89 & .89 & .80 & .89 \\
\hline
\end{tabular}

Notes: $\mathrm{SD}=$ standard deviation; ROE = Regulation of emotion; UOE = Use of emotion; SEA = Self-emotion appraisal; OEA = Other's emotion appraisal.

There are also relatively weak associations between OEA scores and the Positive Attitudes toward Technology ( $\mathrm{r}=0.10$; $\mathrm{p}<0.001$ ) (Table 5). No relationship was established between the specialty of students and all subscales of the WLEIS.

\section{DISCUSSION}

The current study is the first of its kind in Lebanon and aims to investigate the factors associated with EI among the young university students. The results of the study reveal that the respondents have high level of EI. Secondly, the respondents were also reported to have high level of emotional intelligence for all the four domains investigated in this study which indicate that the respondents were highly aware of their own emotions and feelings and they understood that emotions can evolve depending on situations, they could plan and anticipate what emotion is likely to transpire under certain circumstances [9], [40]. However, in contrast with Mohzan et al. [40], the results show that the respondents had less awareness of their own emotions as compared to the awareness of others' emotions. 
TABLE 4. WLEIS SUBSCALES SCORES OF THE YOUTH STUDENTS' SUBGROUPS

\begin{tabular}{|c|c|c|c|c|c|}
\hline \multirow[b]{2}{*}{ Variables } & \multirow[t]{2}{*}{$\overline{\mathrm{N}}$} & \multicolumn{4}{|c|}{$\begin{array}{c}\text { WLEIS subscales } \\
\text { Mean (SD) }\end{array}$} \\
\hline & & SEA & OEA & UOE & ROE \\
\hline \multicolumn{6}{|l|}{ Gender } \\
\hline Male & 183 & $5.29(1.27)$ & $5.43(1.14)$ & $5.59(1.17)$ & $5.01(1.40)$ \\
\hline Female & 522 & $5.21(1.35)$ & $5.63(1.05)$ & $5.72(1.14)$ & $5.06(1.38)$ \\
\hline $\mathrm{P}$ value & & .483 & .03 & .20 & .70 \\
\hline \multicolumn{6}{|l|}{ University } \\
\hline Private & 205 & $5.0(1.31)$ & $5.35(1.15)$ & $5.59(1.21)$ & $4.73(1.43)$ \\
\hline Public & 500 & $5.32(1.32)$ & $5.67(1.03)$ & $5.72(1.12)$ & $5.18(1.35)$ \\
\hline $\mathrm{P}$ value & & .0004 & $<.001$ & .156 & $<.001$ \\
\hline \multicolumn{6}{|l|}{ CGPA } \\
\hline $0-49$ & 21 & $4.76(1.84)$ & $4.96(1.36)$ & $4.62(1.71)$ & $4.63(1.66)$ \\
\hline $50-69$ & 300 & $5.46(1.23)$ & $5.72(1.04)$ & $5.78(1.05)$ & $5.15(1.37)$ \\
\hline $70-100$ & 321 & $5.06(1.37)$ & $5.48(1.08)$ & $5.68(1.16)$ & $5.00(1.37)$ \\
\hline $\mathrm{P}$ value & & .0001 & .001 & .0001 & .133 \\
\hline \multicolumn{6}{|c|}{ Living with parents } \\
\hline Yes & 632 & $5.25(1.33)$ & $5.60(1.08)$ & $5.73(1.11)$ & $5.05(1.40)$ \\
\hline No & 73 & $5.04(1.29)$ & $5.34(1.06)$ & $5.23(1.35)$ & $4.98(1.28)$ \\
\hline$P$ value & & .201 & .072 & .001 & .67 \\
\hline \multicolumn{6}{|c|}{ Physical activity } \\
\hline Yes & 438 & $5.39(1.26)$ & $5.63(1.04)$ & $5.82(1.09)$ & $5.23(1.32)$ \\
\hline No & 267 & $4.97(1.40)$ & $5.48(1.14)$ & $5.46(1.21)$ & $4.74(1.44)$ \\
\hline $\mathrm{P}$ value & & $<.0001$ & .067 & $<.0001$ & $<.0001$ \\
\hline \multicolumn{6}{|c|}{ Alcohol drinkers } \\
\hline Yes & 99 & $5.07(1.31)$ & $5.30(1.23)$ & $5.31(1.39)$ & $4.78(1.37)$ \\
\hline No & 606 & $5.25(1.33)$ & $5.62(1.05)$ & $5.74(1.10)$ & 5.09 (1.39) \\
\hline $\mathrm{P}$ value & & .210 & .007 & $<.0001$ & .04 \\
\hline \multicolumn{6}{|l|}{ Smoking } \\
\hline Yes & 142 & $5.12(1.41)$ & $5.41(1.24)$ & $5.46(1.36)$ & $4.69(1.52)$ \\
\hline No & 563 & $5.23(1.31)$ & $5.62(1.03)$ & $5.74(1.08)$ & $5.14(1.34)$ \\
\hline$P$ value & & .291 & .04 & .009 & .001 \\
\hline
\end{tabular}

Notes and abbreviations: SEA = Self-emotion appraisal; OEA = Other's emotion appraisal; UOE = Use of emotion; ROE = Regulation of emotion; usage CGPA=Cumulative Grade Point Average.

TABLE 5. SPEARMAN'S CORRELATION BETWEEN WLEIS SUBSCALES AND ATTITUDES RELATED TO MEDIA AND TECHNOLOGY USAGE SUBSCALES ( $\mathrm{N}=705)$

\begin{tabular}{lllll}
\hline \hline Attitudes related to media and technology usage subscales & SEA & OEA & UOE & ROE \\
\hline Positive Attitudes To Technology & .05 & $\mathbf{. 0 9}$ & .04 & .04 \\
\hline Dependence on Technology & -.06 & -.03 & $\mathbf{- . 1 5}$ & $\mathbf{- . 1 5}^{* * *}$ \\
\hline Negative Attitudes To Technology & -.02 & .05 & -.02 & -.02 \\
\hline Task Switching & -.01 & -.03 & .00 & .00 \\
\hline \hline
\end{tabular}

Notes and abbreviations: $\mathrm{N}=$ Total count; SEA = Self-emotion appraisal; OEA = Other's emotion appraisal; UOE = Use of emotion; ROE = Regulation of emotion.

This study has undertaken rigorous processes to translate and culturally adapt the WLEIS to the Lebanese Arab context; however, the Arabic version of the scale was evaluated and showed good psychometric properties. In general, the acceptability was very good. This reinforces the expected validity (face validity), confirms the absence of problems related to translation [28] and suggest that young students are willing and able to provide good-quality data regarding their EI [41]. The results obtained in this study showed that all dimensions have good reliability. The internal consistency generally exceeded the recommended minimum alpha coefficient standard for group comparison of 0.70 [28], [36] , [38], and is similar to the reliability of the WLEIS in Hong Kong [7] , Malaysia [13], and Korea [42] , and higher than those calculated in Chili [43]. The Arabic version of the WLEIS retained the original four-factor structure and added support for the reliability of the scale [7]. The presence of a relation between the dimensions of WLEIS and the sociodemographic characteristics is an important finding as such instruments could be used in therapeutic evaluations and support the construct validity of the instrument [37], [44]. Construct validity was also evaluated by relating the WLEIS scale with the attitudes related to media and technology subscales where the Dependence on Technology was negatively associated with the UOE and ROE scales scores.

The EI construct may be universal but we agree that behaviors resulting from the EI of an individual may vary across cultures [7]. Since the WLEIS was originally developed in Hong Kong, cross-cultural studies should be done in order to establish its reliability and validity when used with populations of different sociocultural backgrounds, and resulting in East-West response differences [42]. As in Morocco [3] and in Malaysia [13] , the Arabic version of the WLEIS is a valid and reliable measure of ability EI which can be used by researchers and educators to measure and develop EI in Lebanon. It can also be used by students themselves to reflect on their emotional functioning with a perspective that allows them to identify their strengths and weaknesses. 
Furthermore, it increases their emotional awareness and adaptability to effectively handle emotionally charged situations during day to day interactions with patients, peers, and other professionals [10].

Our study results showed that there was no significant difference in EI among students on the basis of gender except the OEA scale scores that was higher for the female students. This fact is in agreement with results of previous studies [26], [42], but not with those of Al-Huwailah et al [45] and who, in contrary to our results, found significant association between males and females in favor of the female students. Research proves that women tend to show greater knowledge of emotional experiences, provide more complex descriptions about emotions, and use a broader emotional vocabulary [12]. Demographic variables such as age and gender have been widely studied with respect to EI, leading sometimes to conflicting results, with some studies reporting higher EI scores among females and other investigations finding no clear differences between males and females [26]. For instance, it has already been demonstrated that there was a significant age difference in regard to emotional abilities [12], [26], [43]. EI should increase with age due to the accumulation of knowledge about emotion and its social context [12]. Mayer et al also showed with a series of studies, that EI increased with age and experience, which qualifies it as an ability rather than a personality trait [7]. This finding was not replicated in our sample that globally included a category of young students ranged from 17 to 30 years.

Our study found that low academic performance and alcohol dependence and smoking were associated with low EI; whereas being physically active and studying in public university were associated with high EI.

Our study results showed that EI had a significant positive effect on academic performance. It was in line with other findings supported by a number of authors that argue that EI can predict academic success [9], [11], [12], [22]. In concordance with our findings, Mohzan et al [40] reveal that only two domains (SEA and UOE) of the EI investigated are found to be significantly and positively associated with the respondents' academic achievement. This finding indicates that students who are well aware of their feelings and emotions and have the ability to understand those emotions as well as to anticipate what emotions would transpire under certain circumstances are better able to cope effectively with the pressures for academic excellence in higher learning institutions [40]. So, increasing youth' EI skills could help them in their high school years, as well as create the psychological resources they need to successfully transition to the workforce [9]. The emotional competence can be taught and effectively learned by students in higher education, constituting a commitment to teach not only theoretical knowledge but also skills that students can use to achieve their personal, academic, professional goals [18] and leadership [5]. However, it is generally known that EI without sufficient intelligence quotient (IQ) in academics cannot help the students to perform well and such approach is very narrow and hinders in lifelong learning and professional achievements [46]. Our findings did not report any relation between specialty and EI. However, Özlü and al [22] reported that the EI level was determined to be lower in natural science students and moderate in students of health and social sciences.

The university students who are involved in physical activity have better EI score for all the WLEIS dimensions, except for Others' emotion appraisal subscale. This suggests that regular sports practice and experience in practicing seem to constitute elements favoring enhanced emotional abilities [26]. In addition, the sport participation could contribute to EI training [9]. Laborde et al [9] found that, together, the five main abilities of EI: identifying, expressing, understanding, regulating, and using emotions of EI promote better quality relationships, health, and performance [9]. All of the previous subjects are related directly to the EI which is a vital component of the mental health [23]. Furthermore, the mental health is related to the physical health [15]. It is boosted as long as the body and the mind are in harmony, and this harmony is achieved through high emotional intelligence.

The current research showed an inverse and significant relationship between the attitude toward technology and EI which is important for social functioning beyond intellectual ability and personality factors [12]. Yekefallah et al [19] reached similar results $(r=-0.16, P=0.003)$. Individuals with a high level of EI know how to evolve in different situations. This ability makes it possible to regulate the emotions and resist unnecessary behaviors such as addiction [19]. Young people have the ability to understand and analyze their emotional experiences and those of their peers.

Multiple perspectives in comparison of private and public universities stated that the private sector differs to their counterpart in terms of funding, ownership, orientation including teaching, research, resources and accreditations, the wider access, and quality of higher education [46]. In his study, Khan [46] concluded that public university students possess insignificant IQ but a significant EI with them. On the other hand, the private university students possess a fair and sufficient IQ with a high EI in them, indicating they will flourish with good CGPAs and also in their professional lives. Private university students are also the most potential candidates in the job market with rational employability skills in them.

\section{LIMITATIONS}

There were some potential limitations of the current study. Due to sampling difficulties (people were not likely to participate when asked in a random sampling method), we had to ask for permission in a university context. Thus, we finally had a convenience sample [3]. The design effect of a cluster sample was not calculated. Also, this is a crosssectional study which cannot establish a temporal relationship between individual characteristics and EI.

\section{CONCLUSION}

The results support the psychometric properties of the WLEIS Arabic version. Psychologists and practitioners in the Arab world could use the WLEIS as a valid and reliable instrument. The youths' EI is affected by socio-demographic and behavioral characteristics, academic achievement, and attitudes related to media and technology usage. Every 
university and college should implement learning assistance centers designed to provide students with a variety of academic supports. Thus, individuals working with students in the context of improving academic skills may want to routinely assess EI of their students in order to improve education, student development, personal well-being, and mental ability.

\section{ACKNOWLEDGMENT}

We are grateful to the subjects who participated in this survey, Mrs. F. Badran for her help and advice on the manuscript, and Mrs. D. Zorkot for her participation in the data collection. We are grateful to the Directors of faculties who helped to carry out this study.

\section{CONFLICTS OF INTEREST}

The authors declare no conflicts of interest regarding the publication of this paper.

\section{AUTHORS' CONTRIBUTIONS}

This work was conducted in collaboration between all the authors. IS designed the study and performed the statistical analysis, and wrote the first draft of the manuscript. HS managed the data analyses of the study, participated in interpretation of data and assisted with the writing. RK, SS and $\mathrm{RB}$ participated in the data collection and interpretation of the data. SS, SB and ND participated in the data analyses of the study, managed literature searches, assisted with the writing. All authors read and approved the final manuscript.

\section{REFERENCES}

[1] C.-S. Wong, P.-M. Wong and K. S. Law, "Evidence of the practical utility of Wong's emotional intelligence scale in Hong Kong and mainland China," Asia Pacific J Manage, vol. 24, p. 43-60, 2007.

[2] E. G. Ezekiel J. Emanuel, "Does Medicine Overemphasize IQ?," JAMA, 29 january 2018.

[3] K. E. Ghoudani, M. Pulido-Martos and E. Lopez-Zafra, "Measuring emotional intelligence in Moroccan Arabic: the Wongand Law Emotional Intelligence Scale / Medidas de la inteligencia emocional en árabe marroquí: la escala de inteligencia emocional de Wong y Law," Revista de Psicología Social / International Journal of Social Psychology, 2017, pp. 1-21, 2017.

[4] N. G. Alghamdi, M. Aslam and K. Khan, "Personality Traits as Predictor of Emotional Intelligence among the University Teachers as Advisors," Hindawi Education Research International, vol. 2017, p. 6 pages, 2017.

[5] C.-S. Wonga and K. S. Law, "The effects of leader and follower emotional intelligence on performance and attitude:An exploratory study," The Leadership Quarterly, vol. 13, pp. 243-247, 2002.

[6] P. v. d. Merwe, S. Coetzee and M. d. Beer, "Measuring emotional intelligence (EQ): a construct comparison between the Bar-On EQ-i and the OPQ32i EI report," Southern African Business Review 2005 9(2): 34 5 50, vol. 9, no. 2, pp. 34-50, 2005.

[7] K. S. Law, C.-S. Wong and L. J. Song, "The Construct and Criterion Validity of Emotional Intelligence and Its Potential Utility for Management Studies," Journal of Applied Psychology, vol. 89, no. 3, p. 483-496, 2004.

[8] J. M. A. Landa and E. López-Zafra, "The Impact of Emotional Intelligence on Nursing:An Overview," Psychology, vol. 1, pp. 5058,2010 .
[9] S. Laborde, E. Mosley, S. Ackermann, A. Mrsic and F. Dosseville, "Emotional Intelligence in Sports and Physical Activity: An Intervention Focus," in Emotional Intelligence in Education. Integrating Research with Practice, Switzerland, The Springer Series on Human Exceptionality, 2019, pp. 289-320.

[10] N. Naeem and A. Muijtjens, "Validity and reliability of bilingual EnglishArabic version of Schutte self report emotional intelligence scale in an undergraduate Arab medical student sample," Medical Teache, vol. 37:sup1, pp. S20-S26, 2015.

[11] B. Mallery, "What is Emotional Intelligence? 2 Theories and Measures," $2017 . \quad$ [Online]. Available: http://positivepsychology.org.uk/emotional-intelligence-mayersalovey-th. [Accessed 1311 2018].

[12] M. S. mieja, J. Orzechowski and M. S. Stolarski, "TIE: An Ability Test of Emotional Intelligence," PLOS ONE, vol. 9, no. 7, p. e103484., 2014.

[13] W. S. W. Sulaiman and M. Z. M. Noor, "International Conference on Social Sciences \& Humanities (ICOSH-UKM2012)Theme: Knowledge for Social Transformation \& Development in the 21st Century.EXAMINING THE PSYCHOMETRIC PROPERTIES OF THE WONG AND LAW EMOTIONAL INTELLIGENCES SCALE (WLEIS)," Journal of Special Sciences and Humanities, no. Special Issue 2, pp. 81-90, 2015.

[14] D. Shouhed, C. Beni, N. Manguso, W. W. IsHak and B. L. Gewertz., "Association of Emotional Intelligence With Malpractice Claims (Abstract)," JAMA Surg., vol. 154, no. 3, pp. 250-256, 2019.

[15] I. Sabbah, H. Sabbah, R. Khamis, S. Sabbah and N. Droubi, "Health related quality of life of university students in Lebanon: Lifestyles behaviors and socio-demographic predictors," Health, vol. 5, no. 7A4, pp. 1-12, 2013.

[16] J. Montgomery, A. McCrimmon, E. Climie and M. Ward, "Emotional Intelligence in Atypical Populations: Research and School-Based Interventions," in Emotional Intelligence in Education. Integrating Research with Practice, Switzerland, The Springer Series on Human Exceptionality, 2019, pp. 243-288.

[17] H. Sabbah, R. Berbari, R. Khamis, D. Zorkot, S. Sabbah, N. Droubi and I. Sabbah, "The Social Media and Technology Addiction and Its Associated Factors among University Students in Lebanon Using the Media and Technology Usage and Attitudes Scale (MTUAS)," Journal of Computer and Communications, 2019, 7,, vol. 7, pp. 88106, 2019.

[18] R. Gilar-Corbí, T. Pozo-Rico, B. Sánchez and J. L. Castejón, "Can Emotional Competence Be Taught in Higher Education? A Randomized Experimental Study of an Emotional Intelligence Training Program Using a Multimethodological Approach," Frontiers in Psychology, vol. 9, 2018.

[19] L. Yekefallah, L. Dehghankar, A. Razaghpoor, E. Hasannia, N. Hosseini and M. Mafi, "The prevalence and predictive factors of internet addiction and its relationship with emotional intelligence among medical students," Social Health and Behavior, 2019.

[20] W. AbdelKader, "The relationship between media use, emotional intelligence and adaptation processing of youth in Nursing Faculty," IOSR Journal of Nursing and Health Science (IOSR-JNHS), vol. 6, no. 5, p. 63-77, 2017.

[21] A. G. Crane, R. Taylor, M. Cormier, J. Lean, K.V.Keefer and J. D. A. Parker, "Developing Emotional Intelligence in At-Risk Youth (Abstract)," Personality and Individual Differences, vol. 101:473, 2016.

[22] Z. K. Özlü, G. AvGar, K. Gökalp, S. E. Apay, Ö. F. Altun and A. YurttaG, "Comparison of the Emotional Intelligence Levels of Students Receiving Education in Different Fields," Education Research International, 2016.

[23] O. Alkhadher, "Developing an Arabic Test for Emotional Intellegence and Assessing its Psychometric Charactrestics and Correlations," Psychological Studies 16(2):, vol. 16, no. 2, pp. 259 289, 2006.

[24] O. ELKhadher, "Emotional Intelligence and Psychological Health in A Sample of Kuwaiti College Students," Perceptual and Motors Skills, vol. 104, pp. 923-936, 2007.

[25] A. A. Mohamed, S. E. Khouly and M. Saad, "Reliability and factor structure of a trait emotional intelligence measure in four Arab countries," Education, Business and Society: Contemporary Middle Eastern Issues, vol. 5, no. 1, pp. 83-92, 2012. 
[26] H. Aouani, M. Slimani, N. L. Bragazzi, S. Hamrouni and M. Elloumi, "A preliminary validation of the Arabic version of the "Profile of Emotional Competence" questionnaire among Tunisian adolescent athletes and nonathletes: insights and implications for sports psychology," Psychology Research and Behavior Management, vol. 12 , p. $155-167,2019$.

[27] M. H. Alshehri and A. M. Atoom, "The Relationship between Emotional Intelligence and the Level of Literary Appreciation Skills among Arabic Language Teachers for the Secondary Stage in Najran Region," Journal of Educational and Psychological Studies [JEPS], vol. 13, no. 3, 2019.

[28] I. Sabbah, H. Sabbah, R. Khamis, S. Sabbah and N. Droubi., "Health related quality of life of university students in Lebanon: Lifestyles behaviors and socio-demographic predictors," Health, vol. 5, no. 7A4, pp. 1-12, 2013.

[29] M.-J. Sanchez-Ruiz, C. El-Jor, J. A. KharmaJoelle, M. S. Bassil and N. Zeeni, "Personality, emotion-related variables, and media pressure predict eating disorders via disordered eating in Lebanese university students," Eating and weight disorders: EWD 24(5), 2017.

[30] S. Obeid, M. Akel, C. Haddad, K. Fares, H. Sacre, P. Salameh and S. Hallit, "Factors associated with alexithymia among the Lebanese population: results of a cross crosssectional," BMC Psychology, p. 7:80, 2019

[31] K. E. Hassan and M. E. Sader, "Adapting and Validating the BarOn EQ-i:YV in the Lebanese Context (Abstract)," International Journal of Testing, vol. 5, pp. 301-317, 2005.

[32] F. Kong, "The validity of the Wong and Law Emotional Intelligence Scale in a Chinese sample: Tests of measurement invariance and latent mean differences across gender and age," Personality and Individual Differences, vol. 116, p. 29-31, 2017.

[33] N. Libbrecht, A. D. Beuckelaer, F. Lievens and T. Rockstuhl, "Measurement Invariance of the Wong and Law Emotional Intelligence Scale Scores: Does the Measurement Structure Hold across Far Eastern and European Countries?," Applied Psychology, vol. 63, no. 2, pp. 223-237., 2014.

[34] K.-M. Ng, C. Wang, C. P. Zalaquett and N. Bodenhorn, "A Confirmatory Factor Analysis of the Wong and Law Emotional Intelligence Scale in a Sample of International College Students.," Int J Adv Counselling, vol. 30, p. 131-144, 2008.

[35] C.-S. Wong and K. S. Law., "The effects of leader and follower emotional intelligence on performance and attitude: An exploratory study.," The Leadership Quarterly, vol. 13, pp. 243-274, 2002.

[36] I. Sabbah, N. Drouby, S. Sabbah, N. Retel-Rude and M. Mercier, "Quality of life in rural and urban populations in Lebanon using SF 36 Health Survey," Health and Quality of Life Outcomes, vol. 1: 30, 2003 .

[37] J. E. J. Ware, SF-36 health survey manuel and interpretation guide, Second printing ed., Boston: MA: The Health Institute, New England Center, 1997.

[38] N. JC and B. IH, Psychometric Theory, 3rd ed. ed., New York: McGraw-Hil, 1994.

[39] Y. Xiang, S. Zhao, H. Wang, Q. Wu, F. Kong and L. Mo, "Examining brain structures associated with dispositional envy and the mediation role of emotional intelligence," Scientific Reports, vol. 7:39947, 2017.

[40] M. A. M. Mohzan, N. Hassan and N. A. Halil, "The Influence of Emotional Intelligence on Academic Achievement. 6thInternational Conference on University Learning and Teaching (InCULT 2012)," Procedia - Social and Behavioral Sciences 90 ( 2013 ) 303 - 312, vol. 90, pp. 303-312, 2013.

[41] I. Sabbah, H. Sabbah, S. Sabbah, H. Akoum, N. Droubi and M. Mercier., "Measurement Properties of the Arabic Lebanon Version of the Pediatric Quality of Life Inventory 4.0 Generic Core Scales for
Young Child (5 - 7 years), and Child Aged 8 - 12 Years: Quality of Life in Urban and Rural Children in Lebanon," Creative Education, vol. 3, no. Special Issue,, pp. 959-970, 2012

[42] E. Fukuda, D. H. Saklofske, K. Tamaoka and H. Lim, "Factor Structure of the Korean Version of Wong and Law's Emotional Intelligence Scale," Assessment, vol. 19: 3, 2012.

[43] J. C. Acosta-Pradoab and R. A. Z. Torresc, "Validation of the Wong and Law Emotional Intelligence Scale for Chilean managers," Suma Psicológica, vol. 26, no. 2, pp. 110-118, 2019.

[44] R. Khamis, H. Sabbah, S. Sabbah, L. Peters, N. Droubi and I. Sabbah5, "Evaluating the psychometric properties of the Arabic version of the Groningen Frailty Indicator among Lebanese elderly people," Journal of the Egyptian Public Health Association, vol. 94:28, 2019.

[45] A. Al-Huwailah, " Quality of Life and Emotional Intelligence in a Sample of Kuwait University Students," Journal of Education and Practice, vol. 8, no. 3, pp. 180-185, 2017.

[46] S. Khan, "A comparative analysis of emotional intelligence and intelligence quotient among Saudi business students' toward academic performance," International Journal of Engineering Business Management, vol. 11, pp. 1-10, 2019.

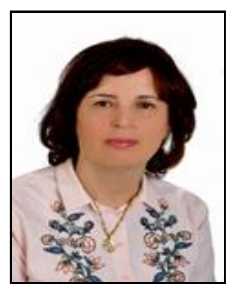

\section{Ibtissam Sabbah}

Educational background: Ph.D. University of Franche-Comté, Besancon, France, 2003 Research Interests:

Health related quality on Life according to gender and urbanization, Health promotion, risk management, biostatistics \& epidemiology 